\title{
Prediction of Rutting Evolution in Flexible Pavement Life Cycle at the Road Network Scale Using an Air-Launched Ground-Penetrating Radar System
}

\author{
F. Tosti \\ School of Computing and Engineering, \\ University of West London \\ St Mary's Road, W5 5RF, London, UK \\ Fabio.Tosti@uwl.ac.uk
}

\author{
A. Benedetto, L. Bianchini Ciampoli, A. Calvi, \\ F. D’ Amico \\ Department of Engineering, Roma Tre University \\ Via Vito Volterra 62, 00146, Rome, Italy \\ andrea.benedetto@uniroma3.it, \\ luca.bianchiniciampoli@uniroma3.it, \\ alessandro.calvi@uniroma3.it, \\ fabrizio.damico@uniroma3.it
}

\begin{abstract}
In this work, the evolution of damages in pavement life cycle relative to rutting has been modeled in relevant pavement sections. Ground-penetrating radar (GPR) surveys were carried out at the rural road network scale using an air-launched pulsed radar system, $1 \mathrm{GHz}$ central frequency of investigation, linked to an instrumented van for collecting data at traffic speed. Surveys were performed in two time periods, six months apart from each other. By knowing the geometrical, traffic, climatic and construction information of each surveyed pavement section, and on the basis of comprehensive literature studies dealing with rutting versus time measurements in several flexible pavement sections during their life cycle, it has been possible to determine a reliable domain of existence by means of rutting versus time prediction curves, in which to locate the pavement sectionspecific prediction curve, case by case. Results have shown reliable relationships, wherein damage prediction is consistent with those suggested by literature.
\end{abstract}

Index Terms - Ground-penetrating radar, GPR, pavement rutting, pavement life cycle, rutting prediction curve.

\section{INTRODUCTION}

Over the past few decades, road engineer activities have been increasingly focused on a proper management of infrastructural assets through effective and efficient maintenance actions, whereas the demand for new constructions is slowly reducing. Overall, three main factors can affect investment in sustainable maintenance practices, namely, i) the lack of economic resources, partly due to Global Economic Crisis impacts, that cause a lowering of the demand for new constructions; ii) well-distributed existing assets that meet the current requirements of mobility, and iii) the progressive aging of existing assets.

A Pavement Management System (PMS) represents the traditional process of planning the maintenance and repair of a roadway network for optimizing the pavement conditions [1]. In this framework, it is worth citing the Pavement
Condition Index (PCI) [2] as the most common indicator when quantifying distress in a PMS. Although it has proved in time to be an effective and efficient approach in pavement asset management, many drawbacks must be mentioned including the inability to i) identify type and cause of the pavement distress, ii) identify any remedial action, iii) indicate specific repair actions, where different types of damage return the same PCI value, and iv) predict the evolution of pavement damage.

\section{A. Pavement Design: the Mechanistic-Empirical Approach}

Within a pavement design perspective, mechanisticempirical approaches combine empirical relationships from field data with theoretical predictions based on the mechanics of materials. In this regard, a recent mechanisticempirical (M-E) method, namely, the Mechanistic-Empirical Pavement Design Guide (MEPDG), has attempted to address some of the limitations of the empirically-based design procedures in the AASHTO Guide for Design of Pavement Structures [3]. The MEPDG was developed under the National Cooperative Highway Research Program (NCHRP) Project 1-37A [4] and has represented a major change within the traditional pavement design procedures, as it encompasses site-specific inputs of traffic, climate, subgrade, and existing pavement conditions, along with the possibility to consider changes in trucking, materials, construction, and design concepts. Other M-E models have been also developed in the literature and have provided very promising results [5]-[7].

\section{B. Pavement Rutting}

Amongst the possible types of pavement damage, rutting is one of the most widespread since it exerts considerable impacts on driving safety and maintenance costs. It is defined as a longitudinal surface depression in the wheel path that may have associated transverse displacements. According to [8], three main levels of severity can be related to rutting; 
namely, low (depth $\geq 0.20$ in. $[\sim 5.1 \mathrm{~mm}]$ and $\leq 0.49$ in. [12.4 $\mathrm{mm}]$ ), medium (depth $\geq 0.50$ in. $[\sim 12.7 \mathrm{~mm}]$ and $\leq 0.99$ in. [25.1 mm]), and high (depth $\geq 1.00$ in. $[\sim 25.4 \mathrm{~mm}])$.

Amongst the possible causes, we can cite i) consolidation or lateral movements of any of the pavement layers or the subgrade under traffic, ii) insufficient design thicknesses, iii) lack of compaction, iv) weaknesses within the pavement layers due to moisture infiltration, and v) weak asphalt mixtures [9].

\section{Pavement Inspection Techniques}

Nowadays, many methods aimed at achieving effective maintenance of road infrastructures still rely on the use of traditional destructive techniques, such as coring, drilling or otherwise removing parts of the structure to allow inner visual inspections (e.g., bridge deck inspections). Notwithstanding their high reliability, they have shown to be expensive and time-consuming. In addition, the results may not be significant over long distances when compared with the larger extent of roads.

Thereby, several non-destructive testing or evaluation (NDT/NDE) techniques have been developed to enable more efficient investigations of road pavements and materials. To cite a few, measurements of strength and deformation properties and physical characteristics of pavements can be provided, respectively, by the light falling weight deflectometer (LFWD) [10-11] and, amongst others, by the time-domain reflectometry (TDR) [12] minor destructive system. Nevertheless, most of these tools for direct and indirect surveying are neither time-efficient nor effective for the inspection and maintenance of roads, since they return only local data.

In this regard, ground-penetrating radar (GPR) is an efficient and high-performance tool of growing interest as it is faster [13], extremely cost-effective [14], it can be performed directly in-situ and does not require remedial actions, thus, it can be broadly employed in large-scale inspections [15]. Basically, it is based on the transmission/reception of electromagnetic (EM) waves in a given frequency band [16].

In pavement engineering, it can be used for many purposes, ranging from physical to geometrical inspections of pavement layers. Amongst the main applications, it is worth citing the evaluation of layer thicknesses [17], the assessment of the damage conditions in Hot-Mix Asphalt (HMA) [18] and load-bearing layers [19], the monitoring of concrete structures [20], and the location of utilities [21]. Important efforts have been also devoted to the evaluation of the volumetric water content within the whole pavement structure [22], [23] and, more recently, to the assessment of clay content in load-bearing layers [24]-[26]. In addition, more recent efforts have been addressed to evaluate the strength and deformation properties of road pavements and materials [27], [28], and towards the GPR-based simulation of pavement faults [29].

Nevertheless, new challenges must still be tackled with respect to a more effective use of GPR for further cutting the costs of road maintenance and for improving the health conditions of roads within a useful timeframe during their life cycle, to avoid any full and costly recovery action.

\section{Methodology AND OBJECTIVES}

In this paper, pavement section-specific curves related to rutting versus time measurements in flexible pavement structures have been determined on the basis of both airlaunched GPR system measurements, performed six months apart from each other, and comprehensive literature studies dealing with this type of damage evolution in several flexible pavement sections during their life cycle.

Four main M-E curves for the estimate of the rutting development versus time have been considered herein. They all exhibit a considerable variation in the conditions of damage evolution with relatively similar environmental, traffic loading and volume conditions. The best fitting functions for the experimental points were retrieved from the above literature studies and, after normalizing the values of rutting, a reliable domain of existence for experimental prediction curves was therefore determined. Subsequently, relevant sections picked out amongst the $160 \mathrm{~km}$ of GPR surveys have enabled us to measure the evolution of pavement rutting over a six months' time scale. Using knowledge of the pavement age and on the basis of the aforementioned fitting functions, it has been possible to determine the prediction curves on rutting versus time for each analyzed section.

\section{GPR PRINCIPLES}

Basically, EM methods rely on the transmission/reflection of short EM impulses, with the antenna systems being able to emit and detect them. With a focus on pavement engineering applications, Fig. 1a represents a typical sketch of GPR signal reflections from a common flexible pavement structure. Accordingly, a relevant waveform relative to the reflections from the layer interfaces is represented in Fig. $1 \mathrm{~b}$.

In this respect, $\mathrm{R}_{0}$ is the surface echo from the air-HMA interface, $R_{1}$ represents the reflection from the HMA-base interface, $R_{2}$ and $R_{3}$ are, respectively, the returns from the base-subbase, and the subbase-subgrade interfaces.

Overall, the wave propagation velocity $v$ in a given pavement layer of thickness $h$ can be computed as $h=$ $(v \cdot \Delta t) / 2$, where $\Delta t$ is the two-way travel time between the pulse reflections of two consecutive layer interfaces. Therefore, the following relationship can be used for the estimate of $v$ :

$$
v=\frac{c}{\sqrt{\varepsilon_{r}}}
$$

where $c$ is the speed of light in free space and $\varepsilon_{r}$ is the relative dielectric permittivity of the investigated medium. Concerning the thickness of the HMA layer, its relative dielectric permittivity can be evaluated as follows [30]: 


$$
\varepsilon_{H M A}=\left[\frac{1+A_{0} / A_{m}}{1-A_{0} / A_{m}}\right]^{2}
$$

where $A_{0}$ is the maximum absolute amplitude of the reflected signal from the HMA surface, $A_{\mathrm{m}}$ is the maximum absolute amplitude reflected from a metal plate placed underneath the radar and larger than its footprint, which acts as a perfect electric conductor (PEC). By considering i) the absolute amplitude values of the interface reflections from the deeper layers (i.e., $R_{1}, R_{2}$ and $R_{3}$ in Fig. $1 b$ ), and ii) the retrieved relative permittivity values of each overlying layer, it is possible to evaluate the dielectrics of the underlying layers [31].

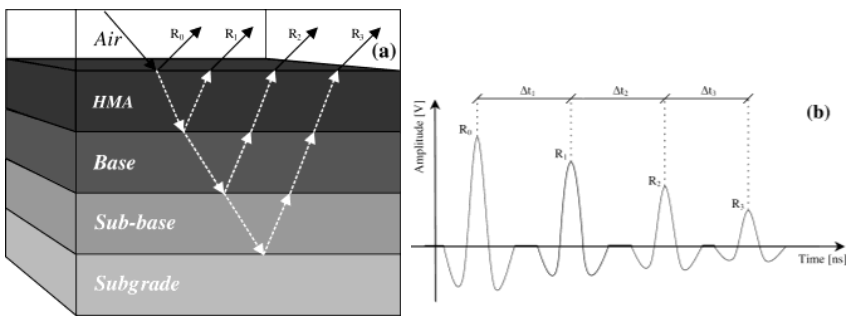

Fig. 1. GPR reflection pattern in flexible pavement structures: (a) trend of reflections in a pavement cross-section; (b) sketch of the relevant waveform

\section{EXPERIMENTAL FRAMEWORK}

\section{A. Tools and Equipment}

The RIS Hi-Pave HR1 1000 air-launched GPR system, manufactured by IDS Ingegneria dei Sistemi S.p.A., was used for the surveying (Fig. 2). It is composed of a monostatic (i.e., operating both as transmitter and receiver) airlaunched antenna, $1 \mathrm{GHz}$ central frequency of investigation, mounted behind an instrumented van hosting the control unit The positioning of data was ensured by a GPS logger, while both an odometer and one HD video camera were employed for measuring the distance covered and for cross-checking the data, respectively. The GRED 3D software by IDS S.p.A. was used for the processing of the GPR data. More information on both the calibration of this radar system and the approach followed for the analyses of the processed radar sections can be found in [14].

\section{B. Study Site}

The rural road network surveyed is located in the District of Rieti, $100 \mathrm{~km}$ north of Rome, Italy, and mostly lies in a hilly and mountainous landscape.

Overall, $160 \mathrm{~km}$ of inspections were carried out at traffic speed in both the travel directions of three main routes, namely, S.R. 79 "Ternana" (Stations: $28+200 \div 45+500$ ), S.R. 313 "di Passo Corese" (Stations: $0+000 \div 45+000-$ one way survey performed), and S.R. 578 "Salto Cicolana" (Stations: $0+000 \div 46+450$ ).

An average temperature of $12{ }^{\circ} \mathrm{C}$ can be considered for the whole network, according to daily observations on the site at the time of the surveys.

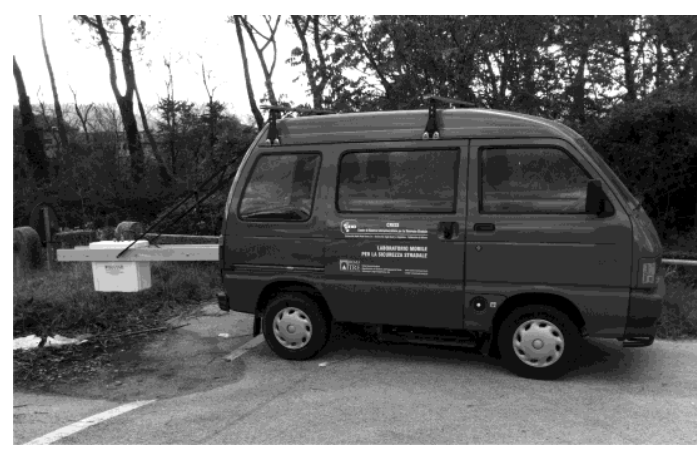

Fig. 2. GPR survey van mounting the air-launched antenna RIS HiPave HR1 1000, manufactured by IDS Ingegneria dei Sistemi S.p.A., Italy

In most of the investigated roadways, the typical carriageway consists of two lanes of $3.75 \mathrm{~m}$ wide, each one provided with a $0.50 \mathrm{~m}$ shoulder. A typical road section is composed of an HMA layer ( $65 \mathrm{~mm}$ of average thickness), a base layer (100 $\mathrm{mm}$ of average thickness), and a subbase layer (300 $\mathrm{mm}$ of average thickness), as outlined by pavement design charts and verified by core drillings. The annual average daily traffic (AADT) amounts to 3000 veh/day.

\section{Modeling OF RUtTING VS TIME DOMAIN OF EXISTENCE}

Four main studies including M-E curves for the estimate of the rutting development versus time are taken into account herein. Firstly, the results from a modeled total rutting performance by means of the NCHRP 1-37A baseline flexible pavement design, as performed in [32], are considered. Such a pavement is a three-layer new construction consisting of an asphalt concrete (AC) surface layer over a non-stabilized graded aggregate base (GAB) layer placed in turn over the subgrade (SG). In such a case study, all of the inputs comply with a Level 3 quality. In [5], an approach combining multilayer elastic analysis to determine key stress and strain values with the results of the WesTrack experiment (i.e., 24 three-layer test sections wherein only rutting could be identified) was developed. Its main goal was to define relevant parameters for evaluating the amount of the permanent strain at a depth of $50 \mathrm{~mm}$ at the outer edge of the tire. In particular, the outcomes from the total predicted rut in section 4 were thoroughly analyzed and have been implemented here in our modeling. Another reference prediction curve has been considered in agreement with [6]. In that study, four main arterial roads from the Swedish long-term pavement performance (LTPP) road network were analyzed to verify the predictability of their degradation behavior using an M-E approach. It was possible to monitor the damaging of these pavements for twenty years, as they were all opened to traffic in the eighties. Amongst them, the four-layer pavement structure of the F-Rv 31 route in Nässjö is considered in our study, and the total rut prediction curve inferred by the model in [33] is taken as a reference within our model. 
TABLE I. MAIN DATA For the M-E APPROACH IMPLEMENTATION ON THE FOUR REFERENCE PAVEMENT SECTIONS

\begin{tabular}{|c|c|c|c|c|c|c|c|}
\hline $\begin{array}{c}\text { Pavement } \\
\text { ID }\end{array}$ & $\begin{array}{c}\text { Surface } \\
\text { Thickness } \\
{[\mathbf{m m}-\mathbf{i n} .]}\end{array}$ & $\begin{array}{c}\text { Base } \\
\text { Thickness } \\
{[\mathbf{m m}-\mathbf{i n} \text {. }}\end{array}$ & $\begin{array}{c}\text { Subbase } \\
\text { Thickness } \\
{[\mathbf{m m}-\mathbf{i n} \text {. }}\end{array}$ & $\begin{array}{c}\text { Subgrade } \\
\text { type }\end{array}$ & $\begin{array}{c}\text { Two-way } \\
\text { AADT } \\
\text { [veh/day }]\end{array}$ & $\begin{array}{c}\text { T } \\
{\left[{ }^{\circ} \mathbf{C}\right]}\end{array}$ & $\begin{array}{c}\text { Age } \\
\text { prediction } \\
\text { spectrum } \\
\text { [month] }\end{array}$ \\
\hline $\begin{array}{c}\text { NCHRP 1-37A } \\
{[32]}\end{array}$ & $135-5.3$ & $323-12.7$ & - & $\begin{array}{c}\text { Highly } \\
\text { compressible } \\
\text { clay }\end{array}$ & 2000 & 23 & 180 \\
\hline $\begin{array}{c}\text { WesTrack } \\
{[5]}\end{array}$ & $152-6.0$ & $305-12.0$ & - & $\begin{array}{c}\text { Compacted } \\
\text { fill } \\
\text { (fine-graded) }\end{array}$ & 20000 & 20 & 26 \\
\hline $\begin{array}{c}\text { F-Rv 31 } \\
{[6]}\end{array}$ & $85-3.3$ & $115-4.5$ & $500-19.7$ & $\begin{array}{c}\text { Glacial till } \\
\text { (organic) }\end{array}$ & 3044 & 6 & 216 \\
\hline $\begin{array}{c}\text { Rv 46 } \\
{[7]}\end{array}$ & $82-3.2$ & $535-21.1$ & - & Gravel & 2000 & 6 & 234 \\
\hline
\end{tabular}

Finally, the fourth prediction curve is derived from [7], wherein an M-E approach was applied to predict damage in three roadways. In this case, our study encompasses the outcomes of the total predicted rutting related to the threelayer structure of route $\mathrm{Rv} 46$ in Trädet.

Table I lists the main construction, traffic volume, and environmental conditions of each pavement section by which a prediction curve was computed and taken as reference in our study.

The whole of these curves has been considered as a comprehensive scenario of variability in the evolution of pavement rutting versus time. Notwithstanding the different conditions of development of this damage, least square curve fitting analyses have highlighted the possibility to use logarithmic functions for describing the growth of rutting depth $(R D)$ in time $t$, as follows:

$$
R D=\alpha \ln t+\beta
$$

In order to analyze effectively the results from the GPR surveys carried out in this study, the absolute values of rutting described by the above reference prediction curves have been normalized, such that a normalized and comparable domain of existence for the development of the pavement rutting has been determined (Fig. 3). Table II lists the main regression parameters found for the normalized reference prediction curves.

By comparing the GPR data of the same pavement section collected in different time periods, it is possible to quantify the total amount of rutting versus time, section by section.

On the basis of the regression model of Eq. 3 and by knowledge of the pavement age, radar investigations properly separated in time may therefore enable the measurement of rutting versus time in relevant sections, and provide points of measured rutting for the construction of pavement section-specific prediction curves.

\section{CASE Study On RUtTING PREDICTION: RESUltS AND SHORT DISCUSSION}

In this paper, a GPR analysis related to one pavement section of Route S.R. 313 "di Passo Corese" is shown in Fig. 4 as a comprehensive outcome from the whole inspection.

Local PMS data indicated a pavement age of 102 months, when the second set of surveys took place.

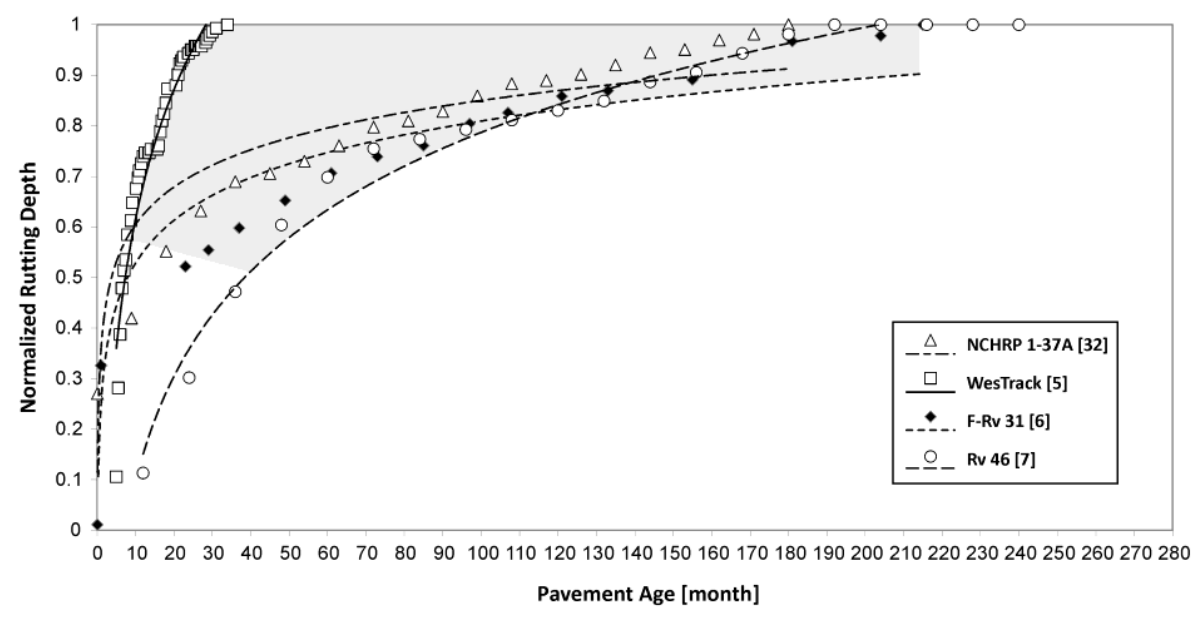

Fig. 3. Domain of existence for normalized rutting versus time prediction curves 


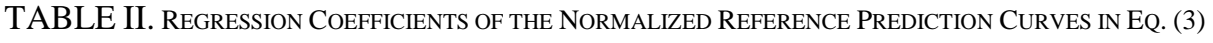

\begin{tabular}{|c|c|c|c|c|}
\hline $\begin{array}{c}\text { Pavement } \\
\text { ID }\end{array}$ & $\begin{array}{c}\text { NCHRP 1-37A } \\
{[\mathbf{3 2}]}\end{array}$ & $\begin{array}{c}\text { WesTrack } \\
\text { [5] }\end{array}$ & $\begin{array}{c}\text { F-Rv 31 } \\
{[\mathbf{6}]}\end{array}$ & $\begin{array}{c}\text { Rv 46 } \\
\text { [7] }\end{array}$ \\
\hline$\alpha$ & 0.11 & 0.37 & 0.12 & 0.30 \\
\hline$\beta$ & 0.36 & -0.23 & 0.25 & -0.59 \\
\hline$R^{2}$ & 0.85 & 0.93 & 0.93 & 0.98 \\
\hline
\end{tabular}

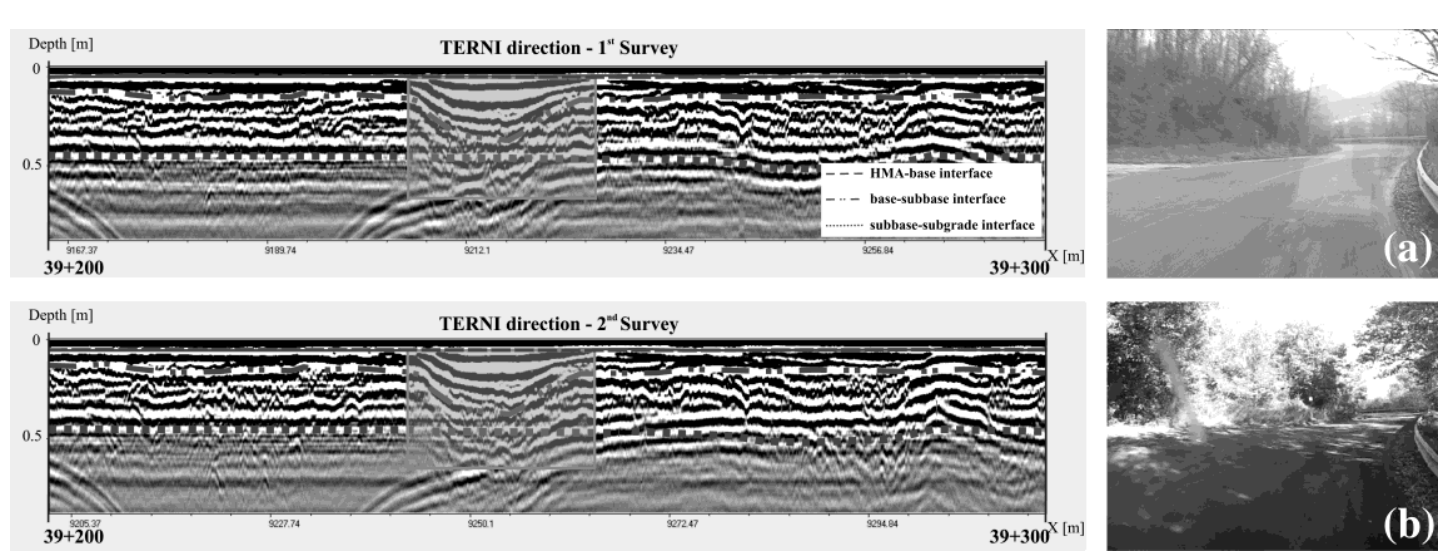

Fig. 4. Rutting localization (i.e., rectangular box) in a 100m segment of processed GPR profiles and relevant pictures from video footage, Route S.R. 313 "di Passo Corese": 1st set of surveys (96 months of pavement age) (a); 2nd set of surveys (112 months of pavement age) (b)

The elevation profile of the road segment is about $470 \mathrm{~m}$ a.s.l. in a typical cut and fill cross-section configuration. Rutting was measured to cover 18.7 m longitudinally along the road axis. The results of the GPR analyses have shown a growth of rutting from $200 \mathrm{~mm}$ (96 months of pavement age) up to $220 \mathrm{~mm}$ (112 months of pavement age) over the sixmonth time scale.

Accordingly, it has been possible to build a logarithmic section-specific prediction curve, as shown in Fig. 5, where the $\alpha$ and $\beta$ parameters equal, respectively, 0.19 and -0.03 . Notwithstanding the availability of few rutting versus time points, it is worth noting the relatively good approximation of the modeled section-specific prediction curve with the reference literature relationships based on a wider dataset. Thereby, it is reasonable to assume an evolution of damage that corresponds to the one modeled.

\section{CONCLUSIONS}

In this paper, a GPR-based approach for the prediction of pavement rutting versus time is proposed.

According to four reference M-E-based studies dealing with rutting development over a flexible pavement life cycle, a comprehensive domain of existence for this type of damage has been modeled. Such a domain was built according to a logarithmic least squares best fitting regression relationship describing the growth of rut depth in time, in agreement with the values consulted from literature. Rutting prediction curves have been therefore inferred by measuring this damage at different time periods by using GPR and by knowledge of the pavement age from local PMS datasets. Promising results from one case study demonstrate the

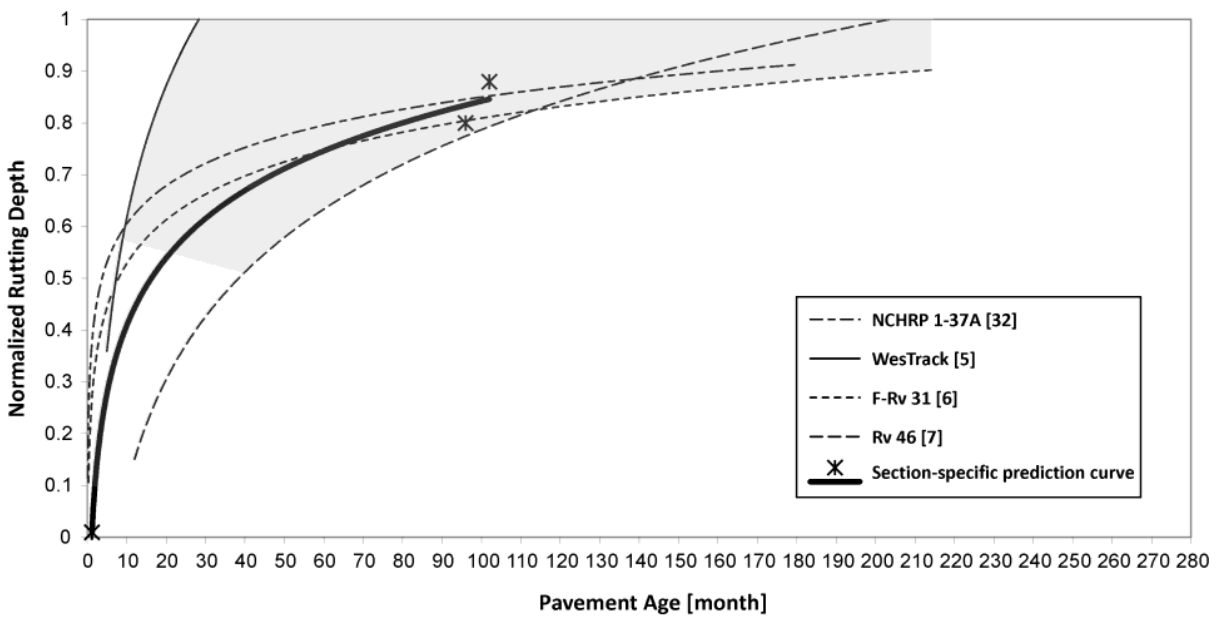

Fig. 5. Section-specific prediction curve, Route S.R. 313 “di Passo Corese”, Stations 39+200 - 39+300 
consistency of the modeled prediction curve with those derived from literature.

The approach used herein may pave the way for an alternative practice with respect to the traditional methods for the estimation of damage, thereby confirming the crucial role of GPR in performing effective and efficient actions that can be exploited in pavement management and maintenance operations.

\section{ACKNOWLEDGMENTS}

The authors would like to thank Mr. Spartaco Cera, from Roma Tre University, for the field assistance during the surveys and for his invaluable help in this study. This work has also benefited from the network activities carried out within the EU funded COST Action TU1208 "Civil Engineering Applications of Ground Penetrating Radar”.

\section{REFERENCES}

[1] Metropolitan Area Planning Council (MAPC) Pavement Management - A Manual for Communities, Contract number MDPW 23892, Federal Highway Administration and the Mass Dpt of Public Works, Boston, Mass, 1986.

[2] American Society for Testing and Materials (ASTM). "Standard Practice for Roads and Parking Lots Condition Index Surveys". ASTM D6433-11 Std, Annual Book of ASTM Standards, 04.03, Philadelphia, USA, 2011.

[3] American Association of State Highway and Transportation Officials (AASHTO). AASHTO Guide for Design of Pavement Structures. AASHTO. Washington, D.C., 1993.

[4] J. Mellela, L. Titus-Glover, M. I. Darter, H. L. Von Quintus, A. Gotlif, M. Stanley, and S. Sadasivam, "Guidelines for implementing NCHRP 1-37A M-E design procedures in Ohio: Volume 1 - summary of findings, implementation plan, and next steps," FHWA/OH-2009/9A, Applied Research Associates, Inc., Champaign, IL, 2009.

[5] J. A. Deacon, J. T. Harvey, I. Guada, L. Popescu, and C. L. Monismith, "Analytically based approach to rutting prediction,” Transport. Res. Rec., TRB, pp. 128-137, 2002.

[6] S. Erlingsson, "Pavement Performance Models (NordFoU PPM): Part 2: Project level modelling of rutting performance -comparison with LTTP road sections," Report NordFou 2.4.1, Linköping, Sweden, 2010.

[7] A. Huvstig, "Model for the prediction of rutting in roads, a NordFou result," Procedia Social and Behavioral Sciences, Elsevier, vol. 48, pp. 2816-2826, 2012.

[8] Federal Highway Administration (FHWA), "Pavement distress identification manual for the NPS road inventory program, 2006 -2009, FHWA, USA, 2009.

[9] Asphalt Institute, Asphalt in pavement preservation and maintenance, MS-16, College Park, Maryland, 2009.

[10] American Society for Testing and Materials (ASTM) "Standard test method for measuring deflections with a Light Weight Deflectometer (LWD)". ASTM E 2583-07 Standard, Annual Book of ASTM Standards, vol. 04.03, Philadelphia, USA, 2011.

[11] A. Benedetto, F. Tosti, and L. Di Domenico, "Elliptic model for prediction of deflections induced by a light falling weight deflectometer," J. Terramech., vol. 49 (1), pp. 1-12, 2012.
[12] D. A. Robinson, S. B. Jones, J. M. Wraith, D. Or, and S. P. Friedman, "A review of advances in dielectric and electrical conductivity measurement in soils using time domain reflectometry," Vadose Zone J., vol. 2 (4), pp. 444-475, 2003.

[13] A. Benedetto, F. D'Amico, and F. Tosti, "Improving safety of runway overrun through the correct numerical evaluation of rutting in Cleared and Graded Areas," Saf. Sci., vol. 1 (62), pp. 326-338, 2014.

[14] F. Tosti, A. Benedetto, and A. Calvi, "Efficient air-launched ground-penetrating radar inspections in a large-scale road network", Sustainability, Eco-efficiency, and Conservation in Transportation Infrastructure Asset Management, Losa and Papagiannakis ed., CRC Press, Pisa, Italy, pp. 703-709, 2014.

[15] A. Benedetto, F. Benedetto, and F. Tosti, "GPR applications for geotechnical stability of transportation infrastructures," Nondestruct. Test. Eva., vol. 27 (3), pp. 253-262, 2012.

[16] D. J. Daniels, Surface-Penetrating Radar, The Institution of Electrical Engineers, London, U.K, 1996.

[17] I. L. Al-Qadi and S. Lahouar, "Use of GPR for thickness measurement and quality control of flexible pavements." J. Assoc. of Asphalt Paving Technologist, vol. 73, pp. 501-528, 2004.

[18] T. Scullion, C. L. Lau, and Y. Chen, "Pavement evaluations using ground penetrating radar," in Proc. 5th International Conference of Ground Penetrating Radar, Kitchener, Canada, 1994, pp. 449-463.

[19] A. Benedetto and F. Tosti, "Inferring bearing ratio of unbound materials from dielectric properties using GPR: the case of Runaway Safety Areas," in Proc., 2013 Airfield and Highway Pavement Conference 2013, LA, USA, June 2013, pp. 13361347.

[20] A. Benedetto, G. Manacorda, A. Simi, and F. Tosti, "Novel perspectives in bridges inspection using GPR." Nondestruct. Test. Eva., vol. 27 (3), pp. 239-251, 2012.

[21] D. Ayala-Cabrera, M. Herrera, J. Izquierdo, and R. PérezGarcía, "Location of buried plastic pipes using multi-agent support based on GPR images." J. Appl. Geophys., vol. 75, pp. 679-686, 2011.

[22] I. L. Al-Qadi, S. Lahouar, A. Loulizi, M. A. Elseifi, and J. A. Wilkes, "Effective approach to improve pavement drainage layers." J. Transp. Eng,. vol. 130 (5), pp. 658-664, 2004.

[23] A. Benedetto, F. Tosti, B. Ortuani, M. Giudici, and M. Mele, "Mapping the spatial variation of soil moisture at the large scale using GPR for pavement applications," Near Surface Geophysics, vol. 13 (3), pp. 269-278, 2015.

[24] C. Patriarca, F. Tosti, C. Velds, A. Benedetto, E. Slob, and S. Lambot, "Frequency dependent electric properties of homogeneous multi-phase lossy media in the groundpenetrating radar frequency range," J. Appl. Geophys., vol. 97, pp. 81-88, 2013.

[25] F. Tosti, C. Patriarca, E. Slob, A. Benedetto, and S. Lambot "Clay content evaluation in soils through GPR signal processing,” J. Appl. Geophys., vol. 97, pp. 69-80, 2013.

[26] F. Tosti, A. Benedetto, L. Bianchini Ciampoli, S. Lambot, C. Patriarca, and E. C. Slob, "GPR analysis of clayey soil behaviour in unsaturated conditions for pavement engineering and geoscience applications," Near Surface Geophysics, vol. 14 (2), pp. 127-144, 2016. 
[27] F. Benedetto and F. Tosti, "GPR spectral analysis for clay content evaluation by the frequency shift method." J. Appl. Geophys., vol. 97, pp. 89-96, 2013.

[28] F. Tosti, S. Adabi, L. Pajewski, G. Schettini, and A. Benedetto, "Large-scale analysis of dielectric and mechanical properties of pavement using GPR and LFWD," in Proc. 15th International Conference of Ground Penetrating Radar (GPR 2014), Brussels, Belgium, Jun, art. no. 6970551, pp. 868-873, Jun 2014.

[29] A. Benedetto, F. Tosti, L. Pajewski, F. D'Amico, and W. Kusayanagi, "FDTD simulation of the GPR signal for effective inspection of pavement damages", in: Proc. of the 15th International Conference on Ground Penetrating Radar, Bruxelles, Belgium, pp. 513-518, doi:10.1109/ICGPR.2014.6970477, July 2014.
[30] K. R. Maser and T. Scullion, "Automated detection of pavement layer thicknesses and subsurface moisture using ground penetrating radar," Transp. Research Board Paper, 1991.

[31] M. C. Loken, "Use of ground penetrating radar to evaluate Minnesota roads," Report MN/RC-2007-01, Minnesota Dpt of Transp, Maplewood, MN, USA, 2007.

[32] B. Christopher, C. Schwartz, and R. Boudreau, "Geotechnical aspects of pavement", Report FHWA NHI-05-037, National Highway Institute, US Federal Highway Administration, Washington, D.C, 2006.

[33] L. Korkiala-Tanttu, "A new material model for permanent deformations in pavements," in Proc., 7th Conference on Bearing Capacity of Roads and Airfields, Trondheim, Norway, 10 pp., 2005. 